\title{
(2) OPEN ACCESS \\ Economic evaluation of direct oral anticoagulants (DOACs) versus vitamin K antagonists (VKAs) for stroke prevention in patients with atrial fibrillation: a systematic review and meta-analysis
}

10.1136/bmjebm-2020-111634

- Additional supplemental material is published online only. To view, please visit the journal online (http:// dx.doi.org/10.1136/ bmjebm-2020-111634).

For numbered affiliations see end of article.

Correspondence to: Dr Sitaporn Youngkong, Mahidol University Faculty of Pharmacy, Bangkok, Thailand; sitaporn.you@mahidol.edu

Check for updates

๑ Author(s) (or their employer(s)) 2021. Re-use permitted under CC BY. Published by BMJ.

To cite: Noviyani R, Youngkong S, Nathisuwan S, et al. BMJ Evidence-Based Medicine Epub ahead of print: [please include Day Month Year]. doi:10.1136/ bmjebm-2020-111634

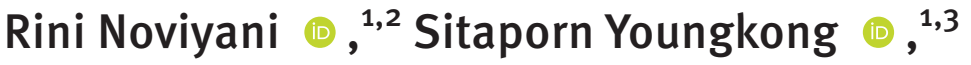 Surakit Nathisuwan $(1),{ }^{4}$ Bhavani Shankara Bagepally $\left({ }^{\circ}, 5\right.$ Usa Chaikledkaew 다, ,,3 Nathorn Chaiyakunapruk 다,

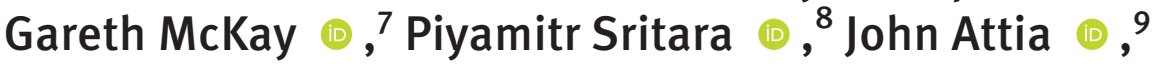 Ammarin Thakkinstian (1) ${ }^{1,10}$}

\section{Abstract}

Objectives To assess cost-effectiveness of direct oral anticoagulants (DOACs) compared with vitamin $\mathrm{K}$ antagonists (VKAs) for stroke prevention in atrial fibrillation (AF) by pooling incremental net benefits (INBs).

Design Systematic review and meta-analysis. Setting We searched PubMed, Scopus and Centre for Evaluation of Value and Risks in Health Registry from inception to December 2019.

Participants Patients with AF.

Main outcome measures The INB was defined as a difference of incremental effectiveness multiplied by willing to pay threshold minus the incremental cost; a positive INB indicated favour treatment. These INBs were pooled (stratified by level of country income, perspective, timehorizon, model types) with a random-effects model if heterogeneity existed, otherwise a fixed effects model was applied. Heterogeneity was assessed using $\mathrm{Q}$ test and $\mathrm{I}^{2}$ statistic. Risk of bias was assessed using the economic evaluations bias (ECOBIAS) checklist.

Results A total of 100 eligible economic evaluation studies (224 comparisons) were included. For highincome countries (HICs) from a third-party payer (TPP) perspective, the pooled INBs for DOAC versus VKA pairs were significantly cost-effective with INBs (95\% CI) of $\$ 6632$ (\$2961.67 to \$10 303.72; $\left.\mathrm{I}^{2}=59.9 \%\right), \quad \$ 6353.24 \quad$ (\$4076.03 to $\$ 8630.45$; $\left.\mathrm{I}^{2}=0 \%\right), \quad \$ 7664.58 \quad(\$ 2979.79$ to $\$ 12 \quad 349.37$; $\mathrm{I}^{2}=0 \%$ ) and $\$ 8573.07$ (\$1877.05 to $\$ 15269.09$; $\mathrm{I}^{2}=0 \%$ ) for dabigatran, apixaban, rivaroxaban and edoxaban relative to VKA, respectively but only dabigatran was significantly cost-effective from societal perspective (SP) with an INB of $\$ 11$ 746.96 ( $\$ 2429.34$ to $\$ 21064.59 ; \mathrm{I}^{2}=52.4 \%$ ). The pooled INBs of all comparisons for upper-middle income countries (UMICs) were not significantly cost-effective. The ECOBIAS checklist indicated that risk of bias was mostly low for most items with the exception of five items which should be less influenced on pooling INBs.

Conclusions Our meta-analysis provides comprehensive economic evidence that allows

\section{Summary box}

What is already known about this subject?

- A large number of economic evaluation studies on direct acting oral anticoagulants (DOACs) and vitamin $\mathrm{K}$ antagonists (VKAs) were conducted in various healthcare settings to guide health policy makers in relation to reimbursement of DOACs.

- The previous systematic reviews that compared DOACs with VKAs for stroke prevention in atrial fibrillation did not provide an overall quantitative synthesis.

\section{What are the new findings?}

- This is the first quantitative metaanalysis of 100 economic evaluations (that included 144 comparisons) of all four DOACs with VKAs applying pooled incremental net benefit.

- Our findings indicated that DOACs might be significantly more costeffective than VKAs in high-income countries using a third-party payer perspective while no DOACs were more cost-effective in upper-middle income countries (UMICs), regardless of any perspective was used.

- We found that country socioeconomic status and the methodological approach used potentially influenced the cost-effectiveness of DOACs compared with VKAs.

policy makers to generalise cost-effectiveness data to their local context. All DOACs may be cost-effective compared with VKA in HICs with TPP perspective. The pooling results produced moderate to high heterogeneity particularly in UMICs. Further studies are required to inform UMICs with SP. 
Summary box

How might it impact clinical practice in the foreseeable future?

- While clinical efficacy and safety of DOACs over VKAs are established, these agents, at their current pricing, are cost-effective only in high -income countries but not in UMICs due partly to the lower socioeconomic status and the small number of studies available.

- Policy makers and pharmaceutical companies should together consider potential pathways to increase access to these useful agents by considering the impact of socioeconomic status on the cost-effectiveness for UMICs and potentially low-income and middle-income countries.

PROSPERO registeration number CRD 42019146610.

\section{Introduction}

Atrial fibrillation (AF), the most common cardiac arrhythmia, ${ }^{1}$ is an important global health issue ${ }^{23}$ with an incidence of 596.2 cases/100 000 population in the Global Burden of Disease Study. ${ }^{3}$ Recent projections based on various national databases suggest that the incidence has doubled or tripled in the past decade. ${ }^{4-6}$ Complications of AF, particularly stroke, lead to significant morbidity and mortality. ${ }^{2}$ Disability-adjusted life years (DALYs) lost due to AF have increased almost linearly during the past 20 years, with a current global estimate of 5.98 million DALYs lost in 2017 alone. $^{2}$

Oral anticoagulants such as vitamin $\mathrm{K}$ antagonists (VKAs, eg, warfarin) and direct oral anticoagulants (DOACs) are the cornerstone of stroke prevention in $\mathrm{AF}^{7}$ VKAs have several limitations including the need for frequent monitoring as a consequence of numerous drug interactions. ${ }^{7}$ DOACs (ie, dabigatran, rivaroxaban, apixaban and edoxaban) were developed to reduce these limitations. Data from controlled trials and real-world studies suggest that DOACs are non-inferior to VKAs and have some advantages $^{89}$ which has led to their recommendation over VKAs in the AF guidelines of many developed countries. ${ }^{1}{ }^{10}$

Multiple cost-effectiveness studies have compared DOACs with VKAs in various healthcare settings to inform health policy including five systematic reviews (SRs) of economic evaluations. ${ }^{11-15}$ However, none have provided an overall quantitative synthesis of their findings. Recently, SR and meta-analysis (SR$\mathrm{MA}$ ) of economic outcomes have been performed by converting incremental cost-effectiveness ratio (ICER) to incremental net benefit (INB), and then pooling across studies. ${ }^{16-18}$ The ICER, estimated by dividing incremental cost with incremental effectiveness, could be interpreted that the intervention is said to be cost-effective if it is lower than the willingness to pay (WTP) threshold. However, the ICER is controversial in some state, that is, a negative ICER may be due to a lower cost but higher effectiveness, or higher cost along with lower effectiveness of the intervention. Therefore, Crespo et $a l^{16}$ had suggested pooling the INB across studies, defined as a difference of incremental effectiveness multiplied by WTP threshold minus the incremental cost, which could be directly interpreted, that is, a positive INB indicated favour the intervention. This quantitative synthesis requires stratification by economic factors (eg, level of country income, time horizon, perspective, economic models and so on) to minimise heterogeneity. ${ }^{17}{ }^{18}$ This SR-MA summarises the costeffectiveness of individual DOACs compared with VKAs for stroke prevention in patients with AF to inform policy decisions in countries with limited resources.

\section{Methods}

This SR-MA was reported in accordance with the Preferred Reporting Items for Systematic Reviews and Meta-Analysis 2020 statement and the review protocol was registered at PROSPERO. ${ }^{19}$

\section{Data sources and search strategy}

We performed a comprehensive search in PubMed, Scopus and Centre for Evaluation of Value and Risks in Health (CEVR) databases from inception to 7 December 2019, see online supplemental appendix 1 . Studies were selected if they met the following criteria included patients with $\mathrm{AF}$, primarily/secondarily aimed to compare VKAs (ie, warfarin or acenocoumarol or phenprocoumon or coumarin) with DOACs (ie, dabigatran, apixaban, rivaroxaban and edoxaban), and reported ICER, quality-adjusted life years (QALYs) or INB. Studies were excluded if they provided insufficient data for synthesis.

\section{Data extraction}

Two investigators (RN and BSB) independently extracted data. Disagreement was resolved in consultation with senior authors (SY and AT). Extracted data included study characteristics, study population, interventions, economic data (ie, perspective, WTP threshold or gross domestic product estimates from the World Bank according to the study year, time-horizon, currency, economic model) and findings. In addition, data for pooling were also extracted including mean cost, incremental cost, clinical effectiveness, incremental effectiveness and ICERs together with SE, or 95\% CI. Incremental costs and effectiveness were also extracted from the cost-effective plane using Web-Plot-Digitizer software V.4.2..$^{20} 21$

\section{Risk of bias}

We assessed risk of bias for included studies using the economic evaluations bias (ECOBIAS) checklist. ${ }^{22}$ The first part evaluated the overall bias which consisted of the following 11 items: narrow perspective, inefficient comparator, cost measurement omission, intermittent data collection, invalid valuation, ordinal ICER, double-counting, inappropriate discounting, limited sensitivity analysis, sponsor and reporting/dissemination. The second part specifically evaluated risk of bias of the model specifications in economic evaluations consisting of three subdomains, that is, structure of the model (four items), data (six items) and consistency (one item). Each item was graded as yes, no, partly, unclear or not applicable, where yes and no referred to high and low risk of bias, respectively.

\section{Data analysis}

The primary outcome of interest was INB. Economic data were harmonised by converting all currency data using purchasing power parity for the year 2019. ${ }^{23}$ In addition, different scenarios were applied to estimate INB and its variance based on the methods suggested by Crespo et $a l^{16}$ (as follows: INB $=\mathrm{K} \times \Delta \mathrm{E}-\Delta \mathrm{C}$ , or INB $=\Delta \mathrm{E} \times(\mathrm{K}-\mathrm{ICER})$ where $\mathrm{K}$ is the WTP threshold, $\Delta \mathrm{C}$ the incremental cost, $\Delta \mathrm{E}$ the incremental effectiveness, ICER the incremental cost and incremental effectiveness ratio), and our expanded methods are published previously, ${ }^{17}{ }^{18}$ see online 
supplemental appendix 2. A positive INB indicated favouring treatment (ie, intervention is cost-effective), whereas a negative INB indicated favouring comparator (ie, intervention is not costeffective). ${ }^{162425}$ Heterogeneity was assessed using the Cochrane-Q test and $\mathrm{I}^{2}$ statistic and considered present if $\mathrm{I}^{2} \geq 25 \%$ or if the $\mathrm{p}$ value was $<0.1$. The INBs were pooled across studies, stratified by country income (classified by the World Bank), ${ }^{20}$ time-horizon, economic model and perspective, using a random-effects model (Der Simonian and Laird method) if heterogeneity was present, or an inverse-variance model if not. ${ }^{26}$

Meta-regression, sensitivity or subgroup analyses were undertaken to explore sources of heterogeneity such as discount rate, WTP threshold, data source and funding source. Publication bias was assessed using Egger's test and funnel plots where number of studies/comparisons was 10 or more. Where a funnel plot was asymmetrical, a contour-enhanced funnel plot was constructed to assess if the asymmetry was due to missing studies or heterogeneity. All analyses were performed using STATA V.16. A two-sided $\mathrm{p}<0.05$ was considered statistically significant except for heterogeneity tests, in which case $\mathrm{p}<0.10$ was used.

\section{Results}

\section{Study selection and characteristics}

Of the 1585 studies identified, 100 met the inclusion criteria. List of 14 excluded studies along with reasons are provided in online supplemental appendix 3 eTable 3.1. Of those, 86,13 and 1 study were conducted in high-income countries (HICs), upper-middle income countries (UMICs) and low/ middle income country, respectively. Comparisons included dabigatran versus warfarin $(\mathrm{N}=49),{ }^{27-75}$ apixaban versus warfarin $(\mathrm{N}=39),{ }^{28-30} 32-4143455162 \quad 65-67697273$ 76-92 rivaroxaban versus warfarin $(\mathrm{N}=34)^{28-30} 32-384041434550515762$ 65-69 7273 83 93-101 and edoxaban versus warfarin $(\mathrm{N}=16)^{28} 30323843455162677273$ 102-106 (see figure 1).

Characteristics are summarised in table 1 and online supplemental appendix 3 eTable 3.2. Most studies used a third-party payer (TPP) perspective ( $\mathrm{N}=83$ ), ${ }^{27}$ 29-35 37-41 43 44 46-53 55-58 60-63 65 67-73 767879 81-89 91-95 9798100102103 105-126 followed by societal perspective (SP) (N=21) 2833364354575964727577809699101104113123125127128 and patient perspective $(\mathrm{N}=4) .{ }^{45} 576674$ Most studies used Markov models and a lifetime-horizon with discounting for both cost and outcomes. About $90 \%$ of studies stated no conflict of interest, and $56 \%$ were funded by pharmaceutical companies.

Clinical and utility parameters were mostly taken from published literature. Country-specific and GDP-based thresholds were used for WTP in 73 27-31 34-41 44 46-49 51 52 54 57-67 70 72 73 76-80 82-85 8889939497 99-101 103-105 107-110 112-115 117-121 123-125127 129 and 23 studies, 33434550 5556686971747581868791959698106116122126128 respectively. Eightyfour studies with 166 comparisons ${ }^{29-32} 34-41$ 44-50 52545657 60-64 66 67 69-71 73-85 87-89 91-94969799100102 104-129 reported increased costeffectiveness with DOACs compared with warfarin/derivatives, in contrast to the remainder (58 comparisons from 24 studies) which did not. $272833-36384043505155585962656872869598101103107$

\section{Risk of bias assessment}

Across all 22 items from the ECOBIAS checklist, 17 items where more than $70 \%$ of studies were graded as low risk of bias, see online supplemental appendix 3 eTable 3.3. Therefore, risk of bias was mostly low for most items with the exception of five items including narrow perspective, double-counting, inappropriate discounting, reporting and dissemination and internal consistency. However, these biases should be less influenced on pooling INBs because they were occurred in both intervention and

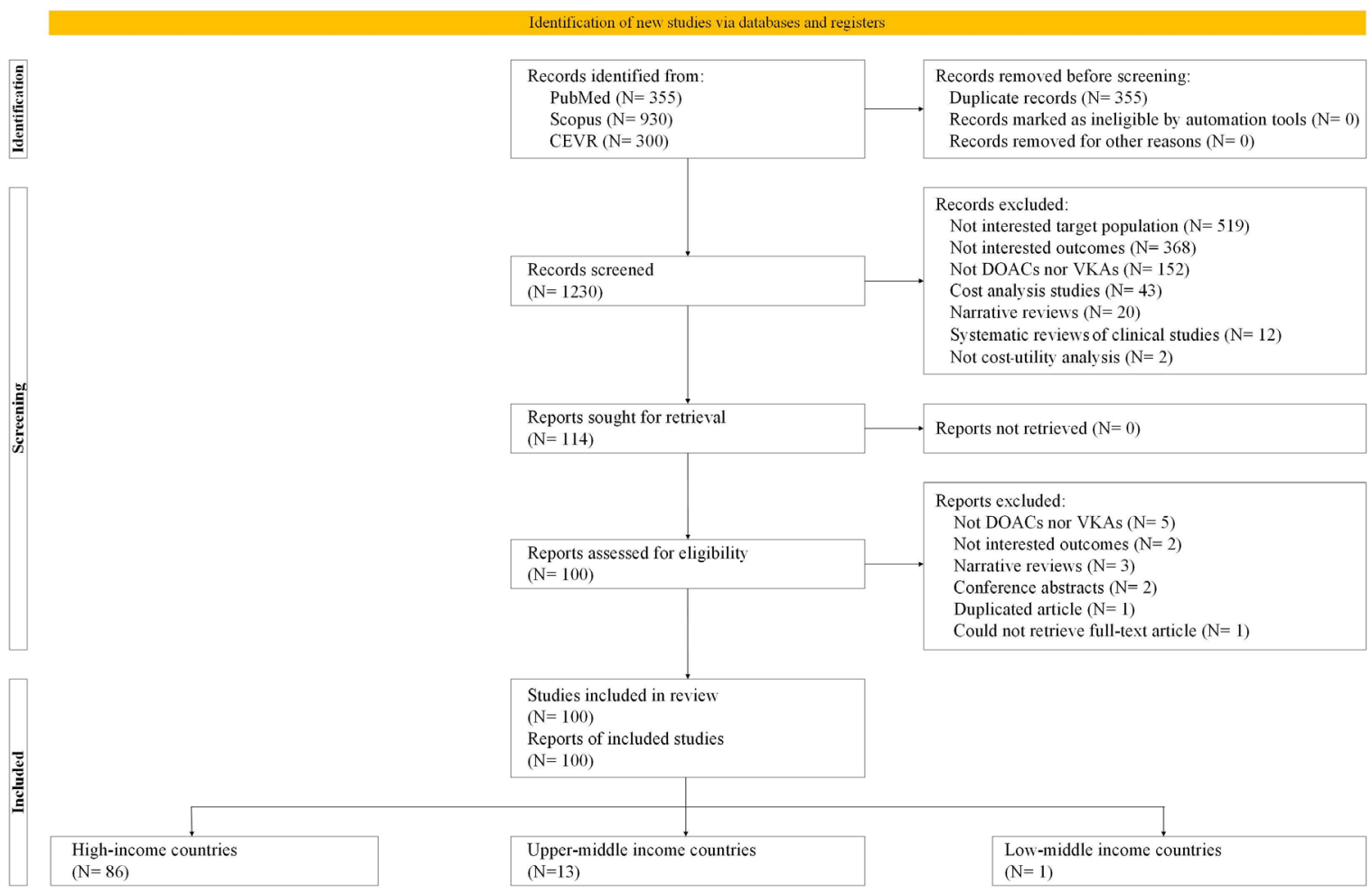

Figure 1 Study selection flow. DOACs, direct oral anticoagulants; VKAs, vitamin K antagonists;CEVR, Centre for Evaluation of Value and Risks in Health databases. 
Table 1 General characteristics of the studies included (created by the authors)

\begin{tabular}{|c|c|c|}
\hline Category & $\begin{array}{l}\text { Number of studies } \\
(\mathrm{N}=100)\end{array}$ & $\begin{array}{l}\text { Number of } \\
\text { comparisons } \\
(n=224)\end{array}$ \\
\hline \multicolumn{3}{|l|}{ Perspective* } \\
\hline Third-party payer & 83 & 175 \\
\hline Societal & 21 & 40 \\
\hline Patients & 4 & 9 \\
\hline \multicolumn{3}{|l|}{ Model type } \\
\hline Markov & 96 & 216 \\
\hline Discrete event simulation & 3 & 7 \\
\hline $\begin{array}{l}\text { Economic evaluation } \\
\text { alongside clinical trial }\end{array}$ & 1 & 1 \\
\hline \multicolumn{3}{|l|}{ Time horizon } \\
\hline Lifetime & 96 & 217 \\
\hline Non-lifetime & 4 & 7 \\
\hline \multicolumn{3}{|l|}{ Discount rate for cost } \\
\hline Not reported & 3 & 12 \\
\hline$\leq 3 \%$ & 53 & 112 \\
\hline $13 \%$ & 44 & 100 \\
\hline \multicolumn{3}{|l|}{ Discount rate for utility* } \\
\hline Not reported & 3 & 11 \\
\hline$\leq 3 \%$ & 58 & 134 \\
\hline $13 \%$ & 40 & 79 \\
\hline \multicolumn{3}{|l|}{ Clinical data source } \\
\hline Published literature & 81 & 181 \\
\hline $\begin{array}{l}\text { Published literature and } \\
\text { evidence synthesis }\end{array}$ & 3 & 17 \\
\hline $\begin{array}{l}\text { Published literature and } \\
\text { registry database }\end{array}$ & 11 & 18 \\
\hline Evidence synthesis & 2 & 5 \\
\hline Registry database & 3 & 3 \\
\hline \multicolumn{3}{|l|}{ Utility data source } \\
\hline Published literature & 93 & 209 \\
\hline $\begin{array}{l}\text { Published literature and } \\
\text { registry database }\end{array}$ & 4 & 11 \\
\hline Survey & 3 & 4 \\
\hline \multicolumn{3}{|l|}{ Currency year } \\
\hline $2008-2013$ & 65 & 133 \\
\hline $2014-2019$ & 35 & 91 \\
\hline \multicolumn{3}{|l|}{ Cost-effectiveness threshold } \\
\hline Country-specific & 73 & 172 \\
\hline $\begin{array}{l}\text { Gross domestic products- } \\
\text { based }\end{array}$ & 23 & 45 \\
\hline Others & 4 & 7 \\
\hline \multicolumn{3}{|l|}{ Cost-effectiveness result* } \\
\hline Cost-effective & 84 & 166 \\
\hline Not cost-effective & 24 & 58 \\
\hline
\end{tabular}

*The total number of studies are more than 100 because individual studies applied multiple methods.

comparator, thus, should be cancelled out when calculation of the INB (a ratio of an incremental cost and QALYs).

\section{Pooling of INB}

\section{Dabigatran versus VKAs}

Based on 40 studies with 48 comparisons in HICs with lifetimehorizon, the pooled INBs were $\$ 6632.70$ from a TPP (95\% CI $\$ 2961.67$ to $\$ 10303.72 ; \mathrm{I}^{2}=59.9 \%$ ) and $\$ 11746.96$ from an SP (95\% CI $\$ 2429.34$ to $\$ 21064.59 ; \mathrm{I}^{2}=52.4 \%$ ). The corresponding

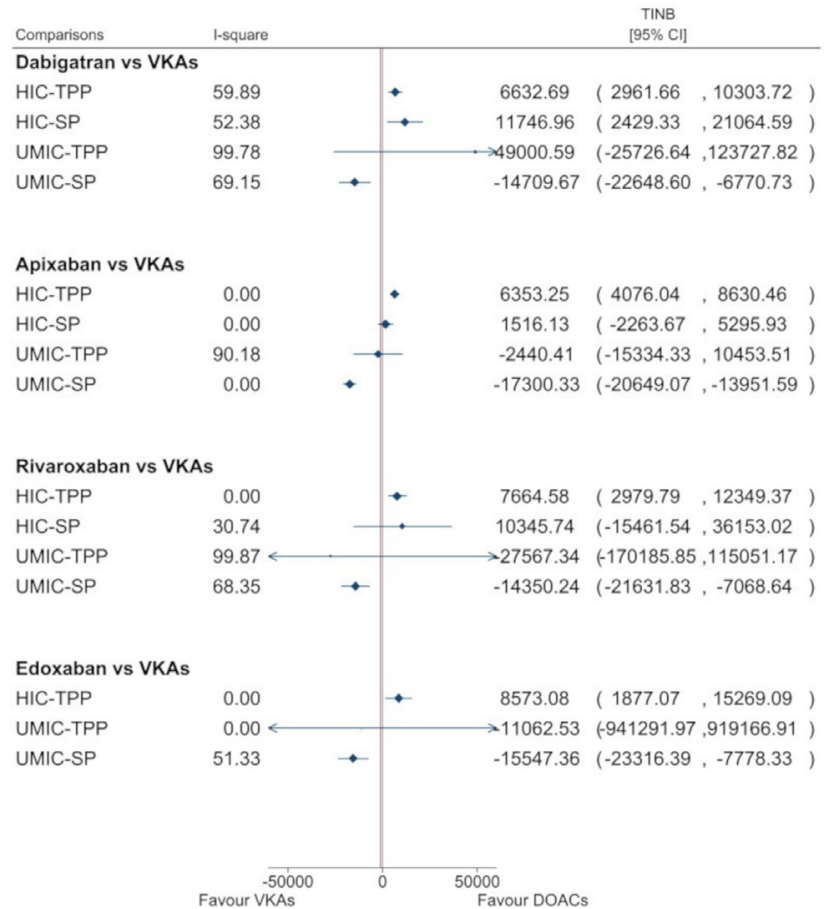

Figure 2 Summary of the pooled INBs of DOACs compared with VKAs classified by country income and perspectives. DOACs, direct oral anticoagulants; HICs, high-income countries; INBs, incremental net benefits; SP, societal perspective; TPP, third-party payer; UMICs, uppermiddle income countries; VKAs, vitamin K antagonists.

pooled INBs in UMICs (nine studies with 13 comparisons) were $\$ 49000.59$ from a TPP (95\% CI $-\$ 25326.64$ to \$124 127.82; $\left.\mathrm{I}^{2}=99.8 \%\right)$ and $-\$ 14709.67$ from an SP (95\% CI $-\$ 22648.61$ to $\left.-\$ 6770.74 ; \mathrm{I}^{2}=69.2 \%\right)$. Dabigatran was cost-effective compared with VKAs in HICs, but not in UMICs (see figure 2, and online supplemental appendix eFigure 4.1-4.4). According to metaregression for HICs, only funding source and WTP could partially explain heterogeneity for TPP and SP whereas heterogeneity in UMICs could not be explained (see online supplemental appendix eTable 4.1). Subgroup analysis by WTP $<\$ 50000$ and funding source from pharmaceutical companies showed that dabigatran was cost-effective compared with VKAs (online supplemental appendix 4 eFigure 4.5-4.6). Publication bias was done in the studies in HICs with TPP indicating no evidence of asymmetry, see online supplemental appendix eFigure 4.7.

\section{Apixaban versus VKAs}

Based on 31 studies (33 comparisons) in HICs, the pooled INBs were $\$ 6353.24$ from a TPP (95\% CI) $\$ 4076.03$ to $\left.\$ 8630.45 ; \mathrm{I}^{2}=0 \%\right)$ and $\$ 1516.13$ from an SP (95\% CI $-\$ 2263.67$ to $\left.\$ 5295.93 ; I^{2}=0 \%\right)$. The corresponding pooled INBs in UMICs (eight studies with 11 comparisons) were $-\$ 2440.41$ from a TPP (95\% CI $-\$ 15334.33$ to $\left.\$ 10453.52 ; \mathrm{I}^{2}=90.2 \%\right)$, and $-\$ 17300.33$ from an SP (95\% CI -\$20 649.07 to $\left.-\$ 13951.59 ; \mathrm{I}^{2}=0 \%\right)$. Apixaban was cost-effective compared with VKAs in HICs with a TPP but not with an SP (see figure 2, and online supplemental appendix eFigures 5.1-5.4). According to meta-regression for UMICs, only discount rates for cost/utility and clinical data source could explain heterogeneity for a TPP whereas the other factors could not explain heterogeneity (see online supplemental appendix eTable 5.1, eFigure 5.5-5.8). There was no evidence of asymmetry using funnel plots and Egger's tests for those studies in HICs with TPP, see online supplemental appendix eFigure 5.9. 


\section{Rivaroxaban versus VKAs}

Based on 26 studies with 28 comparisons in HICs, the pooled INBs were $\$ 7664.58$ from a TPP (95\% CI $\$ 2979.79$ to $\$ 12349.37$; $\left.\mathrm{I}^{2}=0 \%\right)$ and $\$ 10345.74$ from an SP (95\% CI $-\$ 15461.54$, \$36 $153.02 ; \mathrm{I}^{2}=30.7 \%$ ). The corresponding pooled INBs in UMICs (seven studies with 10 comparisons) were $-\$ 27567.34$ from a TPP (95\% CI $-\$ 170185.85$ to $\left.\$ 115051.17 ; I^{2}=99.9 \%\right)$, and $-\$ 14$ 350.24 from an SP (95\% CI $-\$ 21631.83$ to $\left.-\$ 7068.64 ; \mathrm{I}^{2}=68.3 \%\right)$. Rivaroxaban was cost-effective compared with VKAs in HICs with lifetime-horizon from TPP, but not from SP, see figure 2, and online supplemental appendix eFigure 6.1-6.4. Furthermore, rivaroxaban was significantly not cost-effective compared with VKAs in UMICs. According to meta-regression for UMICs with TPP, none of economic factors could explain heterogeneity (see online supplemental appendix eTable 6.1). There was no evidence of asymmetry for pooling INBs in HICs and TPP, see online supplemental appendix eFigure 6.5.

\section{Edoxaban versus VKAs}

Based on 13 studies with 15 comparisons in HICs, the pooled INBs (95\% CI) were $\$ 8573.07$ from a TPP (95\% CI $\$ 1877.05$ to $\$ 15$ 269.09; $\mathrm{I}^{2}=0 \%$ ). The pooled INBs in UMICs (three studies with five comparisons) were $-\$ 11062.53$ from a TPP (95\% CI $-\$ 941$ 291.97 to $\left.\$ 919166.9 ; \mathrm{I}^{2}=0 \%\right)$ and $-\$ 15547.36$ from an SP $(95 \%$ CI $-\$ 23316.39$ to $\left.-\$ 7778.33 ; I^{2}=51.3 \%\right)$. Edoxaban was costeffective compared with VKAs from TPP only in HICs, but not cost-effective in UMICs in both TPP and SP, see figure 2, and online supplemental appendix eFigure 7.1-7.3. Source of heterogeneity could be not explored for pooling in UMICs and SP due to very small number of studies.

\section{Discussion}

This SR-MA assessed whether DOACs were more cost-effective than VKAs for preventing stroke in patients with AF. The INBs were pooled, stratified by country income, economic models, time-horizon, as well as perspective. Data from 100 studies with 224 comparisons of DOACs to VKAs were included. The pooled INBs associated with four DOACs (ie, dabigatran, apixaban, rivaroxaban and edoxaban) from a TPP were significantly more costeffective in HICs compared with VKAs. However, outcomes varied if the evaluation was conducted from an SP; with only dabigatran remaining cost-effective compared with VKAs. Conversely, all DOACs were not cost-effective compared with VKAs in UMICs with SP.

To our knowledge, this is the first SR-MA of cost-effectiveness that includes all four commonly used DOACs providing quantitative economic evidence. Given the variable reporting of economic outcomes, the use of INBs provides direct interpretation and supporting evidence for policy decision making. To minimise the heterogeneity across economic studies, we initially pooled INBs from similar studies based on strata including country incomes, economic model, perspectives and time-horizon. Heterogeneity was therefore reduced in studies from HICs but remained moderate to high in UMICs. This may be due to variation in the characteristics and assumptions that underlie the key model features, different reporting mechanisms, and measures of dispersion for point estimates within individual studies. As such, different approaches, data simulations and variance values were considered from similar studies in our analyses. ${ }^{17} 18$

Our study found that country socioeconomic status and methodological approach used potentially influenced the costeffectiveness of DOACs versus VKAs. DOACs were cost-effective in HICs when the evaluation was conducted using Markov models and lifetime-horizon from TPP-perspective but only dabigatran was cost-effective when using SP. This paradox could be explained by the much smaller number of previous studies analysed from SP in HICs. Moreover, many of them originated from the USA where the WTP thresholds were higher than those from other HICs. Hence, even though DOACs were cost-effective in comparison to VKAs in some individual studies, once their INBs were pooled, the effect was lost.

It is noteworthy that subgroup analyses highlighted that dabigatran was significantly cost-effective compared with VKAs from TPP when WTP thresholds were less than \$50 000. Therefore, policy makers in HICs should consider these conditions in their decision making especially when the SP is preferred or the WTP threshold is less than $\$ 50000$ per QALY.

Our findings confirm the individual economic evaluations in UMICs that all DOACs were less cost-effective than VKAs particularly with SP and low WTP thresholds. However, apixaban might be more cost-effective than VKAs when considered according to WTP threshold. In general, DOACs would not be the optimum choice compared with VKAs in UMICs. Many of the economic evaluations of DOACs versus VKAs for stroke prevention in patients with $\mathrm{AF}$ are represented by diverse methods.

\section{Strengths and weaknesses of the study}

Our study provides comprehensive economic evidence for policy makers to assess cost-effectiveness data in their local context, considering perspectives, time horizons, discounting, sources of data and WTP thresholds. Our study had several limitations. Pooling INBs produced moderate to high heterogeneity particularly in UMICs. A meta-regression could be performed in a few pooling because of small number of studies particularly in UMIC, only a few factors could identify leading to subgroup analysis. Although we considered data from variable scenarios, we were still left with some estimated INBs that had no variances, and we had to 'borrow' the variances from similar studies. Although we limited the extent of heterogeneity by using several simulation methods, this was not possible for studies from UMICs. This highlights a need for uniformity of data reporting in economic analyses, particularly measures of dispersion, to enable SR-MA of economic evaluations. Our findings for rivaroxaban and edoxaban may be limited given the small number of evaluations published. Furthermore, the analyses from UMICs may also be affected by the quality of VKA monitoring; there is evidence that time in therapeutic range is lower in developing countries $^{130-133}$ leading to higher rates of stroke and major bleeding with VKAs. ${ }^{131} 134$ Since clinical trial data under controlled conditions were used in the modelling, DOACs might potentially offer lower benefit in real-world practice for UMICs. The costs relative to hospitalisation are also much lower while drug prices tend to be more expensive in UMICs than HICs which may affect the cost-effectiveness balance of DOACs in UMICs. Changes in DOACs pricing such as the introduction of generic products may also influence our findings. In summary, our findings suggested that DOACs may be cost-effective relative to VKAs in HICs with TPP perspective given that DOACs are clinically non-inferior to VKAs. Our findings are based on studies with low risk of bias for most items, high risk in minor items should be less influenced and cancelled out in INB calculation. Further clinical and cost-effectiveness studies based on real-world clinical data from UMICs are clearly needed. 
Author affiliations

${ }^{1}$ Mahidol University Health Technology Assessment (MUHTA) Graduate Program, Mahidol University, Bangkok, Thailand

${ }^{2}$ Department of Pharmacy, Faculty of Mathematics and Natural Sciences, Udayana University, Bali, Indonesia

${ }^{3}$ Social and Administrative Pharmacy Division, Department of Pharmacy, Faculty of Pharmacy, Mahidol University, Bangkok, Thailand

${ }^{4}$ Clinical Pharmacy Division, Department of Pharmacy, Faculty of Pharmacy, Mahidol University, Bangkok, Thailand

${ }^{5}$ ICMR-National Institute of Epidemiology, Chennai, India

${ }^{6}$ Department of Pharmacotherapy, College of Pharmacy, University of Utah, Salt Lake City, Utah, USA

${ }^{7}$ Centre for Public Health, School of Medicine, Dentistry and Biomedical Sciences, Queen's University, Belfast, UK

${ }^{8}$ Division of Cardiology, Department of Medicine, Faculty of Medicine, Ramathibodi Hospital, Mahidol University, Bangkok, Thailand ${ }^{9}$ School of Medicine and Public Health, Faculty of Health and Medicine, University of Newcastle, New South Wales, New South Wales, Australia ${ }^{10}$ Department of Clinical Epidemiology and Biostatistics, Faculty of Medicine, Ramathibodi Hospital, Mahidol University, Bangkok, Thailand

Contributors RN, BSB, SY and AT conceived and designed the work. RN and BSB did the analysis. RN wrote the first draft of the manuscript with input from SY and AT. All authors interpreted the data, provided critical revision for important intellectual content and approved the final version to be published.

Funding This work was supported by funding from Mahidol University and the International Decision Support Initiative (iDSI) through the doctoral study in Mahidol University Health Technology Assessment (MUHTA) Graduate Programme. This work was produced as part of the iDSI (www.idsihealth.org), which supports countries to get the best value for money from health spending. iDSI receives funding support from the Bill \&t Melinda Gates Foundation and the UK Department for International Development.

Competing interests None declared.

Patient consent for publication Not applicable.

Provenance and peer review Not commissioned; externally peer reviewed.

Data availability statement No data are available. The authors confirm that the data supporting the findings of this study are available within the article and its supplementary materials.

Supplemental material This content has been supplied by the author(s). It has not been vetted by BMJ Publishing Group Limited (BMJ) and may not have been peer-reviewed. Any opinions or recommendations discussed are solely those of the author(s) and are not endorsed by BMJ. BMJ disclaims all liability and responsibility arising from any reliance placed on the content. Where the content includes any translated material, BMJ does not warrant the accuracy and reliability of the translations (including but not limited to local regulations, clinical guidelines, terminology, drug names and drug dosages), and is not responsible for any error and/or omissions arising from translation and adaptation or otherwise.

Open access This is an open access article distributed in accordance with the Creative Commons Attribution 4.0 Unported (CC BY 4.0) license, which permits others to copy, redistribute, remix, transform and build upon this work for any purpose, provided the original work is properly cited, a link to the licence is given, and indication of whether changes were made. See: https://creativecommons.org/licenses/by/4.0/.
ORCID iDs

Rini Noviyani http://orcid.org/0000-0002-9306-2053

Sitaporn Youngkong http://orcid.org/0000-0002-2448-3954

Surakit Nathisuwan http://orcid.org/0000-0003-4828-4412

Bhavani Shankara Bagepally http://orcid.org/0000-0003-0856$767 X$

Usa Chaikledkaew http://orcid.org/0000-0001-9457-9823

Nathorn Chaiyakunapruk http://orcid.org/0000-0003-4572-8794

Gareth McKay http://orcid.org/0000-0001-8197-6280

Piyamitr Sritara http://orcid.org/0000-0003-0509-8943

John Attia http://orcid.org/0000-0001-9800-1308

Ammarin Thakkinstian http://orcid.org/0000-0001-9991-386X

\section{References}

1 Kirchhof P, Benussi S, Kotecha D, et al. 2016 ESC guidelines for the management of atrial fibrillation developed in collaboration with EACTS. Eur J Cardiothorac Surg 2016;50:e1-88.

2 Lippi G, Sanchis-Gomar F, Cervellin G. Global epidemiology of atrial fibrillation: an increasing epidemic and public health challenge. Int $J$ Stroke 2021;16:217-21.

3 Chugh SS, Havmoeller R, Narayanan K, et al. Worldwide epidemiology of atrial fibrillation: a global burden of disease 2010 study. Circulation 2014;129:837-47

4 Patel NJ, Deshmukh A, Pant S, et al. Contemporary trends of hospitalization for atrial fibrillation in the United States, 2000 through 2010: implications for healthcare planning. Circulation 2014;129:2371-9.

5 Kim D, Yang P-S, Jang E, et al. Increasing trends in hospital care burden of atrial fibrillation in Korea, 2006 through 2015. Heart 2018;104:2010-7.

6 Zoni-Berisso M, Lercari F, Carazza T, et al. Epidemiology of atrial fibrillation: European perspective. Clin Epidemiol 2014;6:213-20.

7 Lip GYH, Banerjee A, Boriani G, et al. Antithrombotic therapy for atrial fibrillation: chest guideline and expert panel report. Chest 2018;154:1121-201.

8 Ruff CT, Giugliano RP, Braunwald E, et al. Comparison of the efficacy and safety of new oral anticoagulants with warfarin in patients with atrial fibrillation: a meta-analysis of randomised trials. Lancet 2014;383:955-62.

9 Chan Y-H, Lee H-F, Chao T-F, et al. Real-World comparisons of direct oral anticoagulants for stroke prevention in Asian patients with Non-valvular atrial fibrillation: a systematic review and meta-analysis. Cardiovasc Drugs Ther 2019;33:701-10.

10 January CT, Wann LS, Calkins H, et al. 2019 AHA/ACC/HRS focused update of the 2014 AHA/ACC/HRS guideline for the management of patients with atrial fibrillation: a report of the American College of Cardiology/American heart association Task force on clinical practice guidelines and the heart rhythm Society. J Am Coll Cardiol 2019;74:104-32.

11 Sorensen SV, Peng S, Monz BU, et al. A comparative analysis of models used to evaluate the cost-effectiveness of dabigatran versus warfarin for the prevention of stroke in atrial fibrillation. Pharmacoeconomics 2013;31:589-604.

12 Hesselbjerg LJ, Pedersen HS, Asmussen MB, et al. Is dabigatran considered a cost-effective alternative to warfarin treatment: a review of current economic evaluations worldwide. J Med Econ 2013;16:845-58.

13 Limone BL, Baker WL, Kluger J, et al. Novel anticoagulants for stroke prevention in atrial fibrillation: a systematic review of cost-effectiveness models. PLoS One 2013;8:e62183.

14 Kansal AR, Zheng Y, Pokora T, et al. Cost-Effectiveness of new oral anticoagulants in the prevention of stroke in patients with atrial fibrillation. Best Pract Res Clin Haematol 2013;26:225-37.

15 Pinyol C, Cepeda Jose $\mathrm{M}^{\mathrm{a}}$, Roldan I, et al. A systematic literature review on the cost-effectiveness of apixaban for stroke prevention in Nonvalvular atrial fibrillation. Cardiol Ther 2016;5:171-86.

16 Crespo C, Monleon A, Díaz W, et al. Comparative efficiency research (COMER): meta-analysis of cost-effectiveness studies. BMC Med Res Methodol 2014;14:139. 
17 Bagepally BS, Gurav YK, Anothaisintawee T, et al. Cost utility of sodium-glucose cotransporter 2 inhibitors in the treatment of metformin monotherapy failed type 2 diabetes patients: a systematic review and meta-analysis. Value Health 2019;22:1458-69.

18 Haider S, Chaikledkaew U, Thavorncharoensap M, et al. Systematic review and meta-analysis of cost-effectiveness of rotavirus vaccine in low-income and Lower-Middle-Income countries. Open Forum Infect Dis 2019;6:ofz117.

19 Page MJ, McKenzie JE, Bossuyt PM, et al. The PRISMA 2020 statement: an updated guideline for reporting systematic reviews. BMJ 2021;372:n71.

20 World Bank Data Help Desk. World Bank Country \& Lending Groups. Available: https://datahelpdesk.worldbank.org/knowledgebase/articles/ 906519-world-bank-country-and-lending-groups [Accessed 01 Jun 2020].

21 Rohatgi A. WebPlotDigitizer. Available: https://automeris.io/ WebPlotDigitizer/download.html [Accessed 20 Jul 2019].

22 Adarkwah CC, van Gils PF, Hiligsmann M, et al. Risk of bias in model-based economic evaluations: the ECOBIAS checklist. Expert Rev Pharmacoecon Outcomes Res 2016;16:513-23.

23 International Monetary Fund Home Page. Available: https://www.imf.org/ external/pubs/ft/weo/2019/01/weodata/download.aspx [Accessed October 1st, 2019].

24 Willan AR. Incremental net benefit in the analysis of economic data from clinical trials, with application to the CADET-Hp trial. Eur J Gastroenterol Hepatol 2004;16:543-9.

25 Willan AR, Chen EB, Cook RJ, et al. Incremental net benefit in randomized clinical trials with quality-adjusted survival. Stat Med 2003;22:353-62.

26 DerSimonian R, Laird N. Meta-Analysis in clinical trials revisited. Contemp Clin Trials 2015;45:139-45.

27 Pink J, Lane S, Pirmohamed M, et al. Dabigatran etexilate versus warfarin in management of non-valvular atrial fibrillation in UK context: quantitative benefit-harm and economic analyses. BMJ 2011;343:d6333.

28 Dilokthornsakul P, Nathisuwan S, Krittayaphong R, et al. CostEffectiveness analysis of non-vitamin $\mathrm{K}$ antagonist oral anticoagulants versus warfarin in Thai patients with Non-Valvular atrial fibrillation. Heart Lung Circ 2020;29:390-400.

29 Harrington AR, Armstrong EP, Nolan PE, et al. Cost-Effectiveness of apixaban, dabigatran, rivaroxaban, and warfarin for stroke prevention in atrial fibrillation. Stroke 2013;44:1676-81.

30 López-López JA, Sterne JAC, Thom HHZ, et al. Oral anticoagulants for prevention of stroke in atrial fibrillation: systematic review, network meta-analysis, and cost effectiveness analysis. BMJ 2017;359:j5058.

31 Andrikopoulos GK, Fragoulakis V, Maniadakis N. Economic evaluation of dabigatran etexilate in the management of atrial fibrillation in Greece. Hellenic J Cardiol 2013;54:289-300.

32 Shah A, Shewale A, Hayes CJ, et al. Cost-Effectiveness of oral anticoagulants for ischemic stroke prophylaxis among nonvalvular atrial fibrillation patients. Stroke 2016;47:1555-61.

33 Jarungsuccess S, Taerakun S. Cost-Utility analysis of oral anticoagulants for nonvalvular atrial fibrillation patients at the police General Hospital, Bangkok, Thailand. Clin Ther 2014;36:1389-94.

34 Coyle D, Coyle K, Cameron C, et al. Cost-Effectiveness of new oral anticoagulants compared with warfarin in preventing stroke and other cardiovascular events in patients with atrial fibrillation. Value Health 2013;16:498-506.

35 Pink J, Pirmohamed M, Lane S, et al. Cost-Effectiveness of pharmacogenetics-guided warfarin therapy vs. alternative anticoagulation in atrial fibrillation. Clin Pharmacol Ther 2014;95:199-207.

36 Canestaro WJ, Patrick AR, Avorn J, et al. Cost-Effectiveness of oral anticoagulants for treatment of atrial fibrillation. Circ Cardiovasc Qual Outcomes 2013;6:724-31.

37 Wisløff T, Hagen G, Klemp M. Economic evaluation of warfarin, dabigatran, rivaroxaban, and apixaban for stroke prevention in atrial fibrillation. Pharmacoeconomics 2014;32:601-12.

38 Janzic A, Kos M. Cost effectiveness of novel oral anticoagulants for stroke prevention in atrial fibrillation depending on the quality of warfarin anticoagulation control. Pharmacoeconomics 2015;33:395-408.

39 Zheng Y, Sorensen SV, Gonschior A-K, et al. Comparison of the costeffectiveness of new oral anticoagulants for the prevention of stroke and systemic embolism in atrial fibrillation in a UK setting. Clin Ther 2014;36:2015-28.

40 Lanitis T, Cotté FE, Gaudin AF, et al. Stroke prevention in patients with atrial fibrillation in France: comparative cost-effectiveness of new oral anticoagulants (apixaban, dabigatran, and rivaroxaban), warfarin, and aspirin. J Med Econ 2014;17:587-98.

41 Rognoni C, Marchetti M, Quaglini S, et al. Apixaban, dabigatran, and rivaroxaban versus warfarin for stroke prevention in non-valvular atrial fibrillation: a cost-effectiveness analysis. Clin Drug Investig 2014;34:9-17.

42 Kongnakorn T, Lanitis T, Annemans L, et al. Stroke and systemic embolism prevention in patients with atrial fibrillation in Belgium: comparative cost effectiveness of new oral anticoagulants and warfarin. Clin Drug Investig 2015;35:109-19.

43 Rattanachotphanit T, Limwattananon C, Waleekhachonloet 0, et al. Cost-Effectiveness analysis of direct-acting oral anticoagulants for stroke prevention in Thai patients with Non-Valvular atrial fibrillation and a high risk of bleeding. Pharmacoeconomics 2019;37:279-89.

44 Sorensen SV, Kansal AR, Connolly S, et al. Cost-Effectiveness of dabigatran etexilate for the prevention of stroke and systemic embolism in atrial fibrillation: a Canadian payer perspective. Thromb Haemost 2011;105:908-19.

45 Zhao YJ, Lin L, Zhou HJ, et al. Cost-Effectiveness modelling of novel oral anticoagulants incorporating real-world elderly patients with atrial fibrillation. Int J Cardiol 2016;220:794-801.

46 Langkilde LK, Bergholdt Asmussen M, Overgaard M. Cost-Effectiveness of dabigatran etexilate for stroke prevention in non-valvular atrial fibrillation. applying RE-LY to clinical practice in Denmark. J Med Econ 2012;15:695-703.

47 González-Juanatey JR, Álvarez-Sabin J, Lobos JM, et al. CostEffectiveness of dabigatran for stroke prevention in non-valvular atrial fibrillation in Spain. Rev Esp Cardiol 2012;65:901-10.

48 Chang C-H, Yang Y-HK, Chen J-H, et al. Cost-Effectiveness of dabigatran etexilate for the prevention of stroke and systemic embolism in atrial fibrillation in Taiwan. Thromb Res 2014;133:782-9.

49 Carles M, Brosa M, Souto JC, et al. Cost-Effectiveness analysis of dabigatran and anticoagulation monitoring strategies of vitamin $\mathrm{K}$ antagonist. BMC Health Serv Res 2015;15:289.

50 Wang Y, Xie F, Kong MC, et al. Cost-Effectiveness of dabigatran and rivaroxaban compared with warfarin for stroke prevention in patients with atrial fibrillation. Cardiovasc Drugs Ther 2014;28:575-85.

51 Hospodar AR, Smith KJ, Zhang Y, et al. Comparing the cost effectiveness of non-vitamin $\mathrm{K}$ antagonist oral anticoagulants with Well-Managed warfarin for stroke prevention in atrial fibrillation patients at high risk of bleeding. Am J Cardiovasc Drugs 2018;18:317-25.

52 Wouters H, Thijs V, Annemans L. Cost-Effectiveness of dabigatran etexilate in the prevention of stroke and systemic embolism in patients with atrial fibrillation in Belgium. J Med Econ 2013;16:407-14.

53 Kansal AR, Sorensen SV, Gani R. Cost-Effectiveness of dabigatran etexilate for the prevention of stroke and systemic embolism in UK patients with atrial fibrillation. Heart 2012;98:573-8.

54 Kamel H, Johnston SC, Easton JD, et al. Cost-Effectiveness of dabigatran compared with warfarin for stroke prevention in patients with atrial fibrillation and prior stroke or transient ischemic attack. Stroke 2012;43:881-3.

55 Bergh M, Marais CA, Miller-Jansön H, et al. Economic appraisal of dabigatran as first-line therapy for stroke prevention in atrial fibrillation. $S$ Afr Med J 2013;103:241-5.

56 Pepe Ribeiro de Souza C, Bolzachini Santoni N, Gomes de Melo T, et al. Cost-Effectiveness and cost-utility analyses of dabigatran compared with warfarin in patients with nonvalvular atrial fibrillation and risk factors for stroke and systemic embolism within Brazilian private and public health care systems perspectives. Value Health Reg Issues 2015;8:36-42.

57 Salata BM, Hutton DW, Levine DA, et al. Cost-Effectiveness of dabigatran (150 Mg twice daily) and warfarin in patients $\geq 65$ years with nonvalvular atrial fibrillation. Am J Cardiol 2016;117:54-60.

58 Shah SV, Gage BF. Cost-Effectiveness of dabigatran for stroke prophylaxis in atrial fibrillation. Circulation 2011;123:2562-70. 
59 Freeman JV, Zhu RP, Owens DK, et al. Cost-Effectiveness of dabigatran compared with warfarin for stroke prevention in atrial fibrillation. Ann Intern Med 2011;154:1-11.

60 Chevalier J, Delaitre 0, Hammès F, et al. Cost-Effectiveness of dabigatran versus vitamin $\mathrm{K}$ antagonists for the prevention of stroke in patients with atrial fibrillation: a French payer perspective. Arch Cardiovasc Dis 2014;107:381-90.

61 Nshimyumukiza L, Duplantie J, Gagnon M, et al. Dabigatran versus warfarin under standard or pharmacogenetic-guided management for the prevention of stroke and systemic thromboembolism in patients with atrial fibrillation: a cost/utility analysis using an analytic decision model. Thromb J 2013;11:14.

62 Hernandez I, Smith KJ, Zhang Y. Cost-Effectiveness of non-vitamin K antagonist oral anticoagulants for stroke prevention in patients with atrial fibrillation at high risk of bleeding and normal kidney function. Thromb Res 2017;150:123-30.

63 Clemens A, Peng S, Brand S, et al. Efficacy and cost-effectiveness of dabigatran etexilate versus warfarin in atrial fibrillation in different age subgroups. Am J Cardiol 2014;114:849-55.

64 Davidson T, Husberg M, Janzon M, et al. Cost-Effectiveness of dabigatran compared with warfarin for patients with atrial fibrillation in Sweden. Eur Heart J 2013;34:177-83.

65 Krejczy M, Harenberg J, Marx S, et al. Comparison of cost-effectiveness of anticoagulation with dabigatran, rivaroxaban and apixaban in patients with non-valvular atrial fibrillation across countries. J Thromb Thrombolysis 2014;37:507-23.

66 Pink J, Pirmohamed M, Hughes DA. Comparative effectiveness of dabigatran, rivaroxaban, apixaban, and warfarin in the management of patients with nonvalvular atrial fibrillation. Clin Pharmacol Ther 2013;94:269-76.

67 Thom HHZ, Hollingworth W, Sofat R, et al. Directly acting oral anticoagulants for the prevention of stroke in atrial fibrillation in England and Wales: cost-effectiveness model and value of information analysis. MDM Policy Pract 2019;4:2381468319866828.

68 Chen YF, Han HN. Economic evaluation of dabigatran, rivaroxaban and warfarin in preventing stroke in patients with atrial fibrillation. Chinese Journal of New Drugs 2016;25:1216-24.

69 ÁA G-P. Cost-effectiveness assessment of new oral anticoagulation drugs in patients with non-valvular atrial fibrillation. Revista Colombiana de Cardiologia 2017;24:87-95.

70 Ravasio R, Pedone MP, Ratti M. Cost efficacy analysis of new oral anticoagulant for stroke prevention in non-valvular atrial fibrillation in Italy. PharmacoEconomics - Italian Research Articles 2014;16:1-10.

71 Triana JJ, Castañeda C, Parada L. Cost-Effectiveness of dabigatran compared with warfarin in the treatment of patients with non valvular atrial fibrillation in Colombia. Revista Colombiana de Cardiologia 2016;23:82-6.

$72 \mathrm{Ng}$ SS, Nathisuwan S, Phrommintikul A, et al. Cost-Effectiveness of warfarin care bundles and novel oral anticoagulants for stroke prevention in patients with atrial fibrillation in Thailand. Thromb Res 2020;185:63-71.

73 Táborský M, Tomek A, Cihák R. Cost-efectiveness analysis of FI rst-line NOAC prevention of stroke and systemic embolism in patients with nonvalvular atrial FI brillation. Cor et Vasa 2019;61:354-69.

74 Galvani G, Grassetto A, Sterlicchio S, et al. Cost-Effectiveness of dabigatran Exilate in treatment of atrial fibrillation. J Atr Fibrillation 2015;7:1223.

75 Silva Miguel L, Rocha E, Ferreira J. [Economic evaluation of dabigatran for stroke prevention in patients with non-valvular atrial fibrillation]. Rev Port Cardiol 2013;32:557-65.

76 Ademi Z, Pasupathi K, Liew D. Cost-Effectiveness of apixaban compared to warfarin in the management of atrial fibrillation in Australia. Eur $J$ Prev Cardiol 2015;22:344-53.

77 Kamel H, Easton JD, Johnston SC, et al. Cost-Effectiveness of apixaban vs warfarin for secondary stroke prevention in atrial fibrillation. Neurology 2012;79:1428-34.

78 Athanasakis K, Karampli E, Tsounis D, et al. Cost-Effectiveness of apixaban vs. other new oral anticoagulants for the prevention of stroke: an analysis on patients with non-valvular atrial fibrillation in the Greek healthcare setting. Clin Drug Investig 2015;35:693-705.
79 Dorian P, Kongnakorn T, Phatak H, et al. Cost-Effectiveness of apixaban vs. current standard of care for stroke prevention in patients with atrial fibrillation. Eur Heart J 2014;35:1897-906.

80 Lanitis T, Kongnakorn T, Jacobson L, et al. Cost-Effectiveness of apixaban versus warfarin and aspirin in Sweden for stroke prevention in patients with atrial fibrillation. Thromb Res 2014;134:278-87.

81 Li X, Tse VC, Lau WCY, et al. Cost-Effectiveness of apixaban versus warfarin in Chinese patients with Non-Valvular atrial fibrillation: a reallife and modelling analyses. PLoS One 2016;11:e0157129.

82 Lee S, Mullin R, Blazawski J, et al. Cost-Effectiveness of apixaban compared with warfarin for stroke prevention in atrial fibrillation. PLoS One 2012;7:e47473.

83 Kongnakorn T, Lanitis T, Annemans L. Stroke and systemic embolism prevention in patients with atrial fibrillation in Belgium: comparative cost effectiveness of new oral anticoagulants and warfarin. Clin Drug Investig 2014;35:109-19.

84 Costa J, Fiorentino F, Caldeira D, et al. Cost-Effectiveness of non-vitamin $\mathrm{K}$ antagonist oral anticoagulants for atrial fibrillation in Portugal. Rev Port Cardiol 2015;34:723-37.

85 Liu C-Y, Chen H-C. Cost-Effectiveness analysis of apixaban, dabigatran, rivaroxaban, and warfarin for stroke prevention in atrial fibrillation in Taiwan. Clin Drug Investig 2017;37:285-93.

86 Mendoza JA, Silva FA, Rangel LM. Cost-Effectiveness of new oral anticoagulants and warfarin in atrial fibrillation from adverse events perspective. Revista Colombiana de Cardiologia 2019;26:70-7.

87 Hallinen T, Soini EJ, Linna M, et al. Cost-Effectiveness of apixaban and warfarin in the prevention of thromboembolic complications among atrial fibrillation patients. Springerplus 2016;5:1354.

88 Cowper PA, Sheng S, Lopes RD, et al. Economic analysis of apixaban therapy for patients with atrial fibrillation from a US perspective: results from the ARISTOTLE randomized clinical trial. JAMA Cardiol 2017;2:525-34.

89 Hersi AS, Osenenko KM, Kherraf SA, et al. Cost-Effectiveness of apixaban for stroke prevention in non-valvular atrial fibrillation in Saudi Arabia. Ann Saudi Med 2019;39:265-78.

90 Rudakova AV, Tatarskiı̌ BA. [Cost-effectiveness of apixaban compared to other new oral anticoagulants in patients with non-valvular atrial fibrillation]. Kardiologiia 2014;54:43-52.

91 Giorgi MA, Caroli C, Giglio ND, et al. Estimation of the cost-effectiveness of apixaban versus vitamin $\mathrm{K}$ antagonists in the management of atrial fibrillation in Argentina. Health Econ Rev 2015;5:52.

92 Kamae I, Hashimoto Y, Koretsune Y, et al. Cost-Effectiveness analysis of apixaban against warfarin for stroke prevention in patients with nonvalvular atrial fibrillation in Japan. Clin Ther 2015;37:2837-51.

93 Mensch A, Stock S, Stollenwerk B, et al. Cost effectiveness of rivaroxaban for stroke prevention in German patients with atrial fibrillation. Pharmacoeconomics 2015;33:271-83.

94 Kleintjens J, Li X, Simoens S, et al. Cost-Effectiveness of rivaroxaban versus warfarin for stroke prevention in atrial fibrillation in the Belgian healthcare setting. Pharmacoeconomics 2013;31:909-18.

$95 \mathrm{Wu}$ B, Kun L, Liu X, et al. Cost-Effectiveness of different strategies for stroke prevention in patients with atrial fibrillation in a health resourcelimited setting. Cardiovasc Drugs Ther 2014;28:87-98.

96 Kim H, Kim H, Cho SK, et al. Cost-Effectiveness of rivaroxaban compared to warfarin for stroke prevention in atrial fibrillation. Korean Circ $J$ 2019;49:252-63.

97 Lee S, Anglade MW, Pham D, et al. Cost-Effectiveness of rivaroxaban compared to warfarin for stroke prevention in atrial fibrillation. Am J Cardiol 2012;110:845-51.

98 Dwiprahasto I, Kristin E, Endarti D. Cost effectiveness analysis of rivaroxaban compared to warfarin and aspirin for stroke prevention atrial fibrillation (SPAF) in the Indonesian healthcare setting. Indonesian Journal of Pharmacy 2019;30:74-84.

99 Morais J, Aguiar C, McLeod E, et al. Cost-Effectiveness of rivaroxaban for stroke prevention in atrial fibrillation in the Portuguese setting. Rev Port Cardiol 2014;33:535-44.

100 Hori M, Tanahashi N, Akiyama S, et al. Cost-Effectiveness of rivaroxaban versus warfarin for stroke prevention in non-valvular atrial fibrillation in the Japanese healthcare setting. J Med Econ 2020;23:1-10. 
101 Salcedo J, Hay JW, Lam J. Cost-Effectiveness of rivaroxaban versus warfarin for treatment of nonvalvular atrial fibrillation in patients with worsening renal function. Int J Cardiol 2019;282:53-8.

102 Magnuson EA, Vilain K, Wang K, et al. Cost-Effectiveness of edoxaban vs warfarin in patients with atrial fibrillation based on results of the engage AF-TIMI 48 trial. Am Heart J 2015;170:1140-50.

103 Krejczy M, Harenberg J, Wehling M, et al. Cost-Effectiveness of anticoagulation in patients with nonvalvular atrial fibrillation with edoxaban compared to warfarin in Germany. Biomed Res Int 2015;2015:876923.

104 Nguyen E, Egri F, Mearns ES, et al. Cost-Effectiveness of highdose edoxaban compared with Adjusted-Dose warfarin for stroke prevention in Non-Valvular atrial fibrillation patients. Pharmacotherapy 2016;36:488-95.

105 Rognoni C, Marchetti M, Quaglini S, et al. Edoxaban versus warfarin for stroke prevention in non-valvular atrial fibrillation: a cost-effectiveness analysis. J Thromb Thrombolysis 2015;39:149-54.

106 Vilain KA, Yang MC, Hui Tan EC, et al. Cost-Effectiveness of Edoxaban vs. Warfarin in Patients with Atrial Fibrillation Based on Results of the ENGAGE AF - TIMI 48 Trial: Taiwanese Perspective. Value Health Reg Issues 2017;12:74-83.

107 Verhoef TI, Redekop WK, Hasrat F, et al. Cost effectiveness of new oral anticoagulants for stroke prevention in patients with atrial fibrillation in two different European healthcare settings. Am J Cardiovasc Drugs 2014;14:451-62.

108 Stevanović J, Pompen M, Le HH, et al. Economic evaluation of apixaban for the prevention of stroke in non-valvular atrial fibrillation in the Netherlands. PLoS One 2014;9:e103974.

109 Lip GYH, Kongnakorn T, Phatak H, et al. Cost-Effectiveness of apixaban versus other new oral anticoagulants for stroke prevention in atrial fibrillation. Clin Ther 2014;36:192-210.

110 Pletscher M, Plessow R, Eichler K, et al. Cost-Effectiveness of dabigatran for stroke prevention in atrial fibrillation in Switzerland. Swiss Med Wkly 2013;143:w13732.

111 Miller JD, Ye X, Lenhart GM, et al. Cost-Effectiveness of edoxaban versus rivaroxaban for stroke prevention in patients with nonvalvular atrial fibrillation (NVAF) in the US. Clinicoecon Outcomes Res 2016;8:215-26.

112 Athanasakis K, Boubouchairopoulou N, Karampli E, et al. Cost effectiveness of apixaban versus warfarin or aspirin for stroke prevention in patients with atrial fibrillation: a Greek perspective. Am J Cardiovasc Drugs 2017;17:123-33.

113 Barón Esquivias G, Escolar Albaladejo G, Zamorano JL, et al. CostEffectiveness analysis comparing apixaban and acenocoumarol in the prevention of stroke in patients with nonvalvular atrial fibrillation in Spain. Rev Esp Cardiol 2015;68:680-90.

114 Pradelli L, Calandriello M, Di VR, et al. Cost effectiveness analysis of apixaban versus other NOACs for the prevention of stroke in Italian NonValvular atrial fibrillation patients. Value Health 2014;17:A487-8.

115 Lekuona I, Anguita M, Zamorano JL, et al. Would the use of edoxaban be cost-effective for the prevention of stroke and systemic embolism in patients with nonvalvular atrial fibrillation in Spain? Rev Esp Cardiol 2019;72:398-406.

116 Lanas F, Castro C, Vallejos C, et al. Latin American Clinical Epidemiology Network Series - Paper 2: Apixaban was cost-effective vs. acenocoumarol in patients with nonvalvular atrial fibrillation with moderate to severe risk of embolism in Chile. J Clin Epidemiol 2017;86:75-83.

117 Lip GYH, Lanitis T, Kongnakorn T, et al. Cost-Effectiveness of apixaban compared with edoxaban for stroke prevention in nonvalvular atrial fibrillation. Clin Ther 2015;37:2476-88.
118 Peng S, Deger KA, Ustyugova A, et al. Cost-Effectiveness analysis of dabigatran versus rivaroxaban for stroke prevention in patients with non-valvular atrial fibrillation using real-world evidence in elderly US Medicare beneficiaries. Curr Med Res Opin 2018;34:55-63.

119 Kansal AR, Sharma M, Bradley-Kennedy C, et al. Dabigatran versus rivaroxaban for the prevention of stroke and systemic embolism in atrial fibrillation in Canada. Comparative efficacy and cost-effectiveness. Thromb Haemost 2012;108:672-82.

120 You JHS. Novel oral anticoagulants versus warfarin therapy at various levels of anticoagulation control in atrial fibrillation--a cost-effectiveness analysis. J Gen Intern Med 2014;29:438-46.

121 Canal Fontcuberta C, Betegón Nicolás L, Escolar Albaladejo G. CostEffectiveness analysis of apixaban versus rivaroxaban in the prevention of stroke in patients with non-valvular atrial fibrillation in Spain. Pharmacoeconomics 2015;12:93-103.

122 Rudakova AV, Parfenov VA. Cost-Effectiveness of apixaban compared to warfarin and aspirin in patients with Non-Valvular atrial fibrillation (Nvaf) in the Russian Federation. Value Health 2014;17:A489.

123 de Jong LA, Groeneveld J, Stevanovic J, et al. Cost-Effectiveness of apixaban compared to other anticoagulants in patients with atrial fibrillation in the real-world and trial settings. PLoS One 2019;14:e0222658.

124 de Pouvourville G, Blin P, Karam P. The contribution of real-world evidence to cost-effectiveness analysis: case study of dabigatran etexilate in France. Eur J Health Econ 2020;21:235-249.

125 Oyagüez I, Suárez C, López-Sendón JL, et al. Cost-Effectiveness analysis of apixaban versus edoxaban in patients with atrial fibrillation for stroke prevention. Pharmacoecon Open 2020;4:485-497.

126 Kourlaba G, Maniadakis N, Andrikopoulos G, et al. Economic evaluation of rivaroxaban in stroke prevention for patients with atrial fibrillation in Greece. Cost Eff Resour Alloc 2014;12:5.

127 van Hulst M, Stevanovic J, Jacobs MS, et al. The cost-effectiveness and monetary benefits of dabigatran in the prevention of arterial thromboembolism for patients with non-valvular atrial fibrillation in the Netherlands. J Med Econ 2018;21:38-46.

128 Silva Miguel L, Ferreira J. [Clinical and economic consequences of using dabigatran or rivaroxaban in patients with non-valvular atrial fibrillation]. Rev Port Cardiol 2016;35:141-8.

129 Kansal AR, Sorensen SV, Gani R, et al. Cost-Effectiveness of dabigatran etexilate for the prevention of stroke and systemic embolism in UK patients with atrial fibrillation. Heart 2012;98:573-8.

130 Singer DE, Hellkamp AS, Piccini JP, et al. Impact of global geographic region on time in therapeutic range on warfarin anticoagulant therapy: data from the ROCKET AF clinical trial. J Am Heart Assoc 2013;2:e000 067-e67.

131 Haas S, Ten Cate H, Accetta G, et al. Quality of vitamin K antagonist control and 1-year outcomes in patients with atrial fibrillation: a global perspective from the GARFIELD-AF registry. PLoS One 2016;11:e0164076.

132 Semakula JR, Mouton JP, Jorgensen A, et al. A cross-sectional evaluation of five warfarin anticoagulation services in Uganda and South Africa. PLoS One 2020;15:e0227458-e58.

133 Krittayaphong R, Chantrarat T, Rojjarekampai R, et al. Poor time in therapeutic range control is associated with adverse clinical outcomes in patients with Non-Valvular atrial fibrillation: a report from the nationwide COOL-AF registry. J Clin Med 2020;9:1698.

134 Vestergaard AS, Skjøth F, Larsen TB, et al. The importance of mean time in therapeutic range for complication rates in warfarin therapy of patients with atrial fibrillation: a systematic review and meta-regression analysis. PLoS One 2017;12:e188482. 